\title{
PROBLEMA PEMBELAJARAN DARING SANTRI SEKOLAH DASAR PONDOK PESANTREN BAITUL MAKMUR: TINJAUAN PROSES DAN PRODUK
}

\author{
Zulaehatus Sofiyah \\ STIT Buntet Pesantren Cirebon \\ sofiyah6zulaeha@gmail.com
}

\begin{abstract}
In mid-March, the even semester of the 2019/2020 policy for online learning has begun to be expanded. Obstacles to guidance, means and understanding of students had been be emerging. Learning policy in schools becomes the basis of learning policy in Baitul Makmur boarding school.The success of learning is one of them by looking at the evaluation results in terms of processes and products / learning outcomes. This study uses quantitative-descriptive method with CIPP evaluation model approach. The Result of this discovery is, Change of enforcement policy from no face-to-face in odd semesters to face-to-face one week twice. Making significant changes to students. Especially when the understanding and motivation of learning learners. Overall the online implementation went well and as scheduled. Evaluation of Product or results of online learning stated that students can understand the material described by the companion. However, it has not understood the application of the question given by the teacher.
\end{abstract}

Keywords: evaluation, daring learning, elementary students

\begin{abstract}
Abstrak
Pertengahan maret, semester genap tahun ajaran 2019/2020 kebijakan untuk pembelajaran online/daring sudah mulai digalangkan. Kendala bimbingan, sarana dan pemahaman siswa bermunculan. Kebijakan pembelajaran di sekolah menjadi landasan kebijakan pembelajaran di pondok pesantren Baitul Makmur. Keberhasilan pembelajaran salah satunya dengan melihat hasil evaluasi dari segi proses dan produk/hasil pembelajaran. Penelitian ini menggunakan metode kuantitatif-deskriptif dengan pendekatan model evaluasi CIPP. hasil dari penemuan ini adalah, Perubahan kebijakan pelaksaan dari tidak ada tatap muka di semester ganjil menjadi ada tatap muka satu minggu dua kali. Menjadikan perubahan yang siginifikan pada peserta didik. Terutama padahal pemahaman dan motivasi belajar peserta didik. Secara keseluruhan pelaksanaan daring berjalan dengan baik dan sesuai dengan yang dijadwalkan.Evalusi produk/hasil dari pembelajaran daring menyatakan Peserta didik dapat memahami materi yang diterangkan pendamping. Akan tetapi, kurang memahami penerapan pada soal yang diberikan oleh guru.
\end{abstract}

Kata Kunci: evaluasi, pembelajaran daring, sekolah dasar.

\section{Pendahuluan}

Evaluasi merupakan langkah yang sangat menentukan untuk mengetahui sebuah program atau kegiatan disebut berhasil atau kurang berhasil. Evaluasi kurikulum merupakan salah satu bagian dari evaluasi pendidikan yang memusatkan 
perhatian pada program-program pendidikan untuk peserta didik (Nana Sujana, 2017 : 127). Evaluasi kurikulum dapat diketahui melalui dua dimensi: dimensi program pendidikan (kurikulum ideal yang disusun dalam bentuk kurikulum beserta pedoman pelaksanaan) dan dimensi pelaksanaan kurikulum disekolah (kurikulum aktual) (Nana Sujana, 2017 : 132). Sejak pertengahan maret, semester genap tahun ajaran 2019/2020 kebijakan untuk pembelajaran online/daring sudah mulai digalangkan. Hal tersebut mengakibatkan guru/pendidik bersentuhan secara terus-menerus dengan teknologi informasi.

Para wali siswa pun mau tidak mau menjadi pendamping belajar peserta didik secara sepenuhnya. Berbagai masalah mulai bermunculan. Ketidakmampuan guru dan orang tua siswa menjadi kendala pertama yang sampai sekarang masih menjadi perbincangan hangat. Kemudian, masalah pembiayaan sarana yang dibutuhkan untuk pembelajaran daring. Hal ini, tentu tidak menjadi masalah bagi keluarga menengah keatas dan warga perkotaan. Sebaliknya, hal ini menjadi perkara yang besar dan sensitive bagi keluarga menengah kebawah dan pedesaan yang berlatarbelakang tidak dapat dengan mudah beradaptasi dengan teknologi.

Pembelajaran daring sudah berjalan delapan bulan lamanya. Semua elemen mulai beradaptasi akan tetapi, yang kini menjadi persoalan media atau cara pengajaran guru yang terkendala atas adaptasi teknologi hanya memberi tugas dan video dari you tube untuk dipelajari siswa. Sebuah pengajaran yang terus berulang dan berulang menjadikan siswa merasa jenuuh sehingga muncul masalah baru. Pengerjaan tugas yang seharusnya dikerjakan siswa didampingi orang tua menjadi orangtua yang mengerjakan tugas tersebut dengan daling agar pekerjaan cepat selesai.

Penelitian ini akan membahas dan menganalisis prestasi akademik siswa dilihat dari minat membaca, pemahaman dan minat belajar siswa. Karena, Evaluasi harus dilakukan secara menyeluruhm meliputi kepribadian, ketajaman hafalan, pemahaman, ketulusan, kerajinan, sikap kerjasama, tanggung jawabm dan sebagainya.

Kemudian Anderson Cratwall mengembangkannya menjadi 6 aspek, yaitu mengingat, mengetahui, aplikasi, analisis, kreasi dan evaluasi (Mujib dan Mudzakir, 2008: 215). Pembahasan lainnya, yakni proses pengajaran dan proses penilaian hasil tugas siswa. Dalam hal ini, peneliti menggunkana teori CIPP dari Daniel L. Stufflebeam, tetapi hanya mengambil pada proses dan produk nya saja, karena peneliti hanya melihat dari sisi orang tua dan siswa sebagai objek kebijakan pembelajaran daring. Beberapa komponen saja akan membuat lebih detail dalam menghasilkan informasi.

Evaluasi komponen yang sangat penting untuk menilai sejauh mana dan seberapa baik kurikulum dan proses pembelajaran berjalan secara optimal atau tidak, sehingga akan diperoleh umpan balik tentang kurikulum atau pembelajaran (Munir, 2010, 106). Model evaluasi CIPP juga sejalan dengan prinsip evaluasi pada undang-undang No. 20 tahun 2003 pasal 58 
ayat 1 dan 2 menyatakan bahwa evaluasi merupakan kegiatan pemantauan dan penilaian terhadap proses serta hasil kegiatan belajar mengajar yang dilakukan oleh lembaga mandiri secara berkesinambungan, berkala, menyeluruh, transparan, dan sistemik untuk menilai pencapaian standar nasional pendidikan.

Penekanan pada evaluasi proses adalah menyediakaan informasi untuk evaluator melakukan prosedur monitoring terpilih yang mungkin baru di implementasikan sehingga butir yang kuat dimanfaatkan dan yang lemah dibuang(Sukmadinata, 2004: 65).

Diterangkan lebih rinci, Important objectives of process evaluation include documenting the process and providing feedback regarding (a) the extent to which the planned activities are carried out and (b) whether adjustments or revisions of the plan are necessary. An additional purpose of process evaluation is (c) to assess the extent to which participants accept and carry out their roles (Guili Zhang dkk, 2011: 57).

Penekanan evaluasi produk Product Evaluation is to collect descriptions and judgments of outcomes and relate them to objectives and to context, input, process information, and to interpret their merit, worth, significance, and probity (Daniel L. Stufflebeam, 2007:335). Evaluasi produk mengakomodasi informasi untuk menyakinkan dalam kondisi apa tujuan dapat dicapai dan juga menentukan (Sukmadinata, 2004: 65).

Sejalan dengan itu menurut Daryanto (2012: 88)Evaluasi Produk yakni evaluasi untuk mengetahui hasil yang dicapai baik selama maupun pada akhir pengembangan sistem pendidikan yang bersangkutan. Itu berarti tujuan utama evaluasi produk adalah untuk memastikan sejauh mana kebutuhan semua peserta terpenuhi (Guili Zhang, 2011:66).

Tujuan penelitian untuk mengetahui proses pembelajaran daring dan produk dari pembelajaran daring. Dari tujuan tersebut akan diketahui peningkatan atau penurunan yang terjadi, Menurut Tyler (dalam buku Hamid Hasan, 2012: 36) evaluasi kurikulum memiliki tujuan untuk mengetahui tingkat perubahan, yang dapat diketahui melalui tingkat perbandingannya dari kemampuan awal sampai pada mengikuti proses suatu program.

\section{Metode}

Penelitian ini menggunakan metode kuantitatif-deskriptif dengan pendekatan model evaluasi CIPP dalam hal ini pada evaluasi proses dan produk. Sumber data penelitian yakni seluruh santri P.P. Baitul Makmur yang berusia 7-11 tahun. Metode pengumpulan data menggunakan angket yang diwawancarakan untuk pemahaman.

Skala yang digunakan dalam penelitian ini adalah skala likert dengan empat macam jawab yakni, sangat setuju, setuju, tidak setuju, dan sangat tidak setuju dengan skala 4-1 untuk pertanyaan positif dan skala 1-4 untuk pertanyaan negative. Dianalisis menggunakan distribusi frekuensi, oleh karena itu Peneliti membuat rentan sebagai berikut;

interval $=\frac{\text { range }}{\text { kategori }}$

Range: range (jangkauan/jarak) dengan rumus $\mathrm{X}$ maks $-\mathrm{X}$ min 
Kategori : banyaknya kategori.

$$
\frac{\text { range }}{\text { kategori }}=\frac{3}{4}=0,75
$$

Jadi, interval setiap kategori adalah 0,75. Skor untuk setiap kategori dapat dilihat pada tabel berikut:

Tabel 1

\begin{tabular}{|l|l|}
\hline \multicolumn{1}{|c|}{ Kategori } & \multicolumn{1}{c|}{ Skor } \\
\hline Sangat baik & $3,28-4,0$ \\
\hline Baik & $2,52-3,27$ \\
\hline Kurang baik & $1,76-2,51$ \\
\hline Sangat tidak baik & $1,0-1,75$ \\
\hline
\end{tabular}

Selain menggunakan distribusi frekuensi secara umum peneliti juga menghitung setiap anggapan/jawaban responden dengan memberikan presentase perolehan skor dari hasil angket, menggunakan rumusan sebagai berikut;

$$
P=\frac{F}{N} \times 100 \%
$$

F: frekuensi yang sedang dicari presentasenya

$\mathrm{N}$ : number of case (jumlah freku/ensi/banyaknya individu)

P: angka presentase (Anas Sudijono, 2005, 43).

Sedangkan uji validitas instrument menggunakan rumusan pearson product moment dengan $\mathrm{r}_{\text {tabel }} 0,878$ dengan taraf signifikasi $5 \%$ dan uji reliabilitas instrument peneliti menggunakan bantuan aplikasi W-stat (walisongo statistik) untuk mengetahui uji validitas dan reliabilitas

\section{Hasil dan Pembahasan}

\section{Pelaksanaan pembelajaran daring P.P Baitul Makmur}

Secara garis besar pelaksanaan pembelajaran daring di pondok pesantren Baitul Makmur dilakspeserta didikan pada jam sekolah yakni pada jam 8.00-10.00 WIB. adapaun perubahan jadwal pembelajaran dikarenakan telatnya guru memberikan materi dan tugas. Pembina akan mengumpulkan peserta didik-peserta didik yang kelasnya sama kemudian menerangkan materi di hari itu. Santri menjadi 3 golongan yakni kelas $2 \mathrm{SD}, 4 \mathrm{SD}, 5 \mathrm{SD}$. Maka, 2 pembina akan membagi tugas Pembina A dengan peserta didik kelas 2 sedangkan Pembina B dengan 4 dan 5 SD. Hal ini bertujuan untuk menghindari santri terlalu ketergatungan dengan hand phone.

Proses daring pada semester satu dan dua mengalami beberapa perubahan sistem dari pihak sekolah. Perbedaan juga terjadi pada beberapa pelajaran. Berikut adalah pelaksaan daring;

a. Pelajaran Matematika

Pada jam 7.30 WIB guru memberikan materi melalaui whatsup grup setiap kelasnya. Pemberian materi dari plafom online seperti youtube atau berupa video tentang penjelasan materi matematika. Kemudian guru memberikan soal matematika, agar peserta didik mengerjakan secara mandiri.

Pelaksanaan pelajaran matematika, Pembina akan berusaha memahami terlebih dulu materi yang akan disampaikan. Kemudian, setelah dipahami Pembina akan menerangkan materi tersebut, bagaimana cara mengerjaannya sampai seluruh santri paham. Pembina mendampingi pengerjaan soal yang diberikan dengan begitu santri tidak 
memerlukan hand phone atau perangkat elektronik. Setelah tugas diselesaikan laporan hasil tugas di foto dan dikirimkan melalui WA pribadi guru. Kemudian guru akan menilai hasil dari pengerjaan peserta didik dan dilaporkan kembali pada pembina.

Pelaksaan

tersebut dilakspeserta didikan tidak ada perubahan sampai pada semester genap. Hanya pada semester genap guru menambahkan adanya pertemuan yang dikelompokkan menjadi 4 kelompok dalam 4 hari di rumah beberapa siswa. Hal ini, dikarenakan pemahaman peserta didik diterangkan oleh gurunya lebih dari pada pemahaman dari Pembina.

b. Pelajaran Tematik

Pelajaran tematik berubah dari semester ganjil dan genap. Pada saat semseter ganjil guru secara sepenuhnya memberikan materi, soal pengayaan/remedial diberikan di WAG tanpa ada tatap muka sama sekali. Kemudian siswa menulis jawaban dibuku tulis. Buku tulis tersebut dikumpulkan 1 minggu sekali pada guru di sekolah untuk dikoreksi. Hal ini, menyebabkan peserta didik harus mengakses hanp phone secara bergantian.

Pada semester genap, sistem pembelajaran berubah. Pembelajran tematik tetap daring akan tetapi guru memberikan materi print out setiap sub tema atua seminggu sekali berbarengan dengan pertemuan matematika. Guru hanya akan memberikan soal pengembangan pemahaman materi pembelajaran setiap harinya. Pembina akan menuliskan soal di papan tulis kemudian peserta didik-peserta didik akan menulis dan mencari jawaban dari materi print out yang diberikan.

Cara

pengumpulan tugas/pengkoreksian tugas dari siswa ke guru disemester genap lebih enak dan tersistem karena dengan jelas peserta didik sudah mendapatkan metari bacaan dan sudah adanya pertemuan dengan guru meskipun hanya beberapa jam saja.

c. Pelajaran Agama

Pelajaran agama pada semester ganjil dan genap tidak ada perubahan, sebagian besar masih menggunakan WAG. Mengirimkan materi yang kemudian peserta didik disuruh merangkum/menulis materi tersebut. Hasil dari tulisan peserta didik di foto yang kemudian dikirimkan memalui WA pribadi gurunya. Akan tetapi pada semester genap guru menambahkan tatapmuka disekolah dengan 2 gelombang dari jam 7.3010.00 dilakukan dalam satu hari. Kegiatan yang dilakukan adalah menerangkan materi yang telah ditulis peserta didik saat di rumah.

Pelaksanaan pembelajaran di pondok, Pembina akan mendikte/menuliskan materi yang diberikan guru di papan tulis, kemudian peserta didik menulis dibuku tulis. Sehingga santri tidak perlu untuk melihat hanp phone. 
2. Evalusi Proses Pembelajaran Daring Santri P.P. Baitul Makmur

Berdasakan angket yang ditanyakan secara lisan pada santri usia 7-11 tahun dengan menyatakan bahwa;

\section{Tabel 2}

\begin{tabular}{|c|c|c|c|}
\hline No & Pernyataan & hasil & Kategori \\
\hline 1 & $\begin{array}{l}\text { Saat guru } \\
\text { menerangkan } \\
\text { materi lebih } \\
\text { mudah } \\
\text { dipahami }\end{array}$ & 3.8 & $\begin{array}{l}\text { Sangat } \\
\text { Baik }\end{array}$ \\
\hline 2 & $\begin{array}{l}\text { Materi } \\
\text { pelajaran } \\
\text { lebih paham } \\
\text { diterangkan } \\
\text { oleh pembina }\end{array}$ & 2.5 & Baik \\
\hline
\end{tabular}

Dari dua pertanyaan tersebut dapat peneliti artikan bahwa pemahaman yang diberikan guru dan Pembina pondok sangat jauh berbeda terpaut selisih 1.3. Usaha membimbing peserta didik dan menciptakan lingkungan yang memungkinkan terjadinya proses untuk belajar (Muhammad Fathurrohman, dkk, 2012: 6-7). Pembina dalam hal ini, kurang menciptakan suasana proses pembelajaran sehingga peserta didik kurang memahami tujuan dari pembelajaran itu.

Jika tujuan pembelajaran tidak ditetapakan terlebih dahulu, maka ibarat bus atau mobil yang berjalan tanpa tujuan, pembelajaran tersebut tidak akan berlangsung efektif. Maka guru atau pendidik harus mempunyai kompetensi tertentu agar dapat merumuskan tujuan pembelajaran dengan jelas dan tepat ((Muhammad Fathurrohman, dkk, 2012: 11-12). Sudah jelas Pembina kurangnya pelatihan dengan kompetensi materi/pelajaran sekolah dasar akan sedikit sulit memahami tujuan pembelajaran dan membentuk kondisi pembelajaran yang baik.

Pada angket tentang Pembina sangat memahami karakter dan kebutuhan setiap peserta didik menujukan hasil bahwa Pembina hanya dapat memahami karakter dan kebutuhan sebagian peserta didik dengan nilai rata-rata 2,0 dikategorikan baik. Hal ini memperkuat dalam hal pembelajaran daring Pembina belum sepenuhnya memenuhi kebutuhan peserta didik sehingga motivasi belajar dan ketertaikan belajar pada peserta didik hanya sekedar selesai saja. Pembina dapat menyampaikan materi dengan metode, media dan teknik pembelajaran yang sesuai memiliki ratarata 2,9 kategori baik dengan presentase $100 \%$ (setuju).

Tabel 3

\begin{tabular}{|c|l|l|l|}
\hline No & Pernyataan & hasil & Kategori \\
\hline 1 & $\begin{array}{l}\text { Belajar di sekolah } \\
\text { lebih melelahkan } \\
\text { dari pada online }\end{array}$ & $1,2 \%$ & $\begin{array}{l}\text { Sangat } \\
\text { tidak } \\
\text { setuju }\end{array}$ \\
\hline 2 & $\begin{array}{l}\text { Belajar di sekolah } \\
\text { lebih } \\
\text { menyenangkan } \\
\text { dari pada di } \\
\text { pondok }\end{array}$ & $\begin{array}{l}\text { Sangat } \\
\text { setuju }\end{array}$ \\
\hline \multicolumn{2}{|l|}{ Minat peserta didik belajar dan }
\end{tabular}

membaca lebih terasah dan terarah saat pembelajaran tatapmuka dengan guru dan teman-temannya dibandingkan pembelajaran yang dilakukan dengan daring. Suasana dan lingkungan belajar saling terkait dengan motivasi dan minat belajar. Menurut penuturan Pembina, peserta didik lebih bersemangat saat peserta didik ditugaskan membaca dan 
mengerjakan dengan teman di sekolah dari pada mengerjakan di pondok. Meskipun, pada hakikatnya sama saja, teman pondok juga teman sekolahnya.

Secara keseluruhan pelaksanaan daring berjalan dengan baik dan sesuai dengan yang dijadwalkan. Hanya motivasi peserta didik lebih bersemangat saat pembelajran dilakukan dengan guru dan teman sekelasa mereka. Untuk kelanjutaan dari pembelajaran butir-butir yang lemah yang disebabkan oleh faktorfaktor kemampuan Pembina harus ditingkatkan.

\section{Evaluasi produk pembelajaran daring}

\section{P.P. Baitul Makmur}

Hasil dari pembelajaran daring di pondok dinyatakan dalam beberapa pernyataan angket yang diberikan,

\begin{tabular}{|l|l|l|}
\hline $\begin{array}{l}\text { N } \\
\mathbf{0}\end{array}$ & Pernyataan & Hasil \\
\hline 1 & $\begin{array}{l}\text { Dapat mengerjakan soal } \\
\text { sendiri tanpa bantuan } \\
\text { Pembina }\end{array}$ & $\begin{array}{l}\text { Dapat } \\
\text { menjelasakan/menerangk } \\
\text { an kembali materi yang } \\
\text { dijelasakn nilai bagus }\end{array}$ \\
\hline 3 & $\begin{array}{l}\text { Mendapatkan nenilaian } \\
\text { saat } \\
\text { harian/tengah semester }\end{array}$ & \\
\hline
\end{tabular}

Berdasar dari tiga hasil tersebut peserta didik kurang dapat mengerjakan soal yang diberikan guru tanpa bantuan Pembina. Hal ini menunjukan bahwa peserta didik hanya pemahaman peserta didik hanya sekedar paham tanpa pemahaman yang berarti dan kesan pembelajaran bermakna akan mudah lupa dengan materi yang diajarkan.
Hasil lain menunjukan setelah diterangkan peserta didik dapat menerangkan kembali apa yang dijelaskan. Maka, pada saat diterangkan sebenarnya peserta didik memahami hanya tidak mengerti bagaimana penerapannya. Terbukti hasil penilaian tengah semester ganjil dan genap serta saat penilaian akhir semester peserta didik menunjukan hasil yang kurang memuaskan.

\section{Grafik 1}

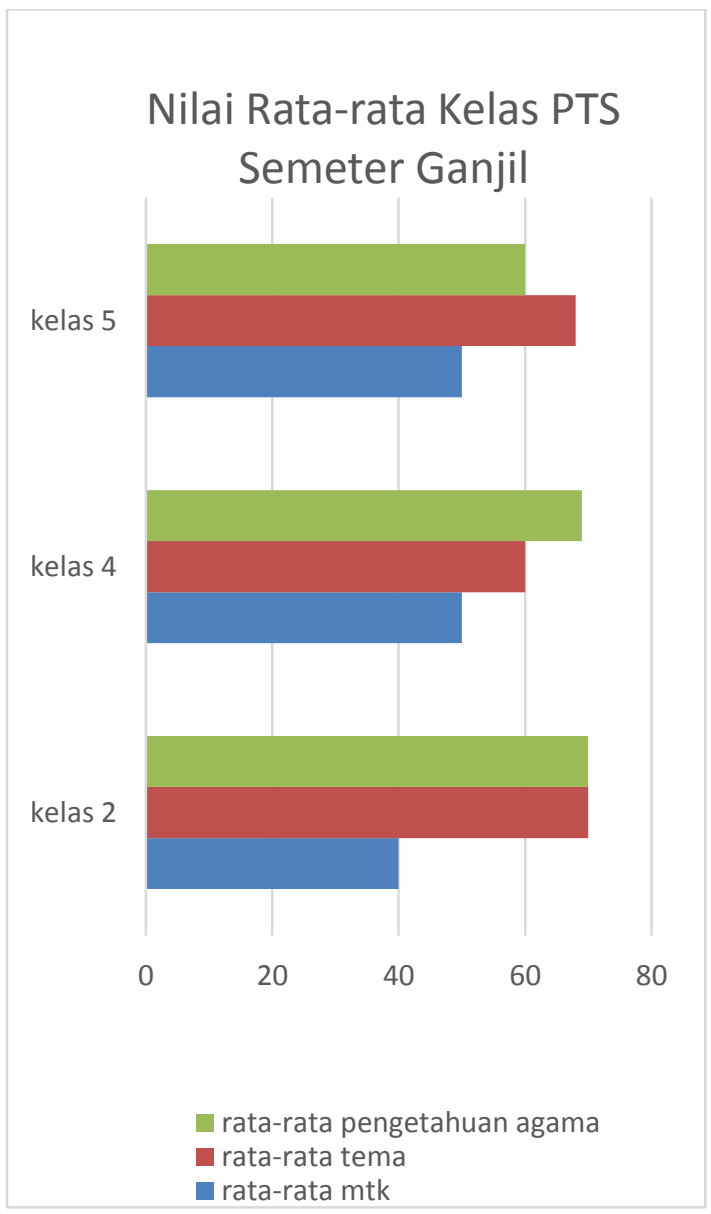

Nilai rata-rata kelas saat semester ganjil sangat signifikan peserta didik yang berprestasi dikleasnya pada semester ini tidak mendapatkan prestasi peserta didik yang prestasinya kurang 
baik pada semester ini peserta didik tersebut mendapat nilai prestasi yang baik. Hal ini, dikarenakan faktor motivasi peserta didik dan pelaksaan daring yang kurang tersistem dengan baik. Tidak ada tatap muka sama sekali di semester ganjil. Sehingga peserta didik hanya memperoleh dari Pembina tanpa penguatan dari gurunya. Adapun kenaikan yang terjadi dikarenakan materi yang sangat mudah dipahami dan diterima peserta didik. Berbeda hal dengan semester genap.

\section{Grafik 2}

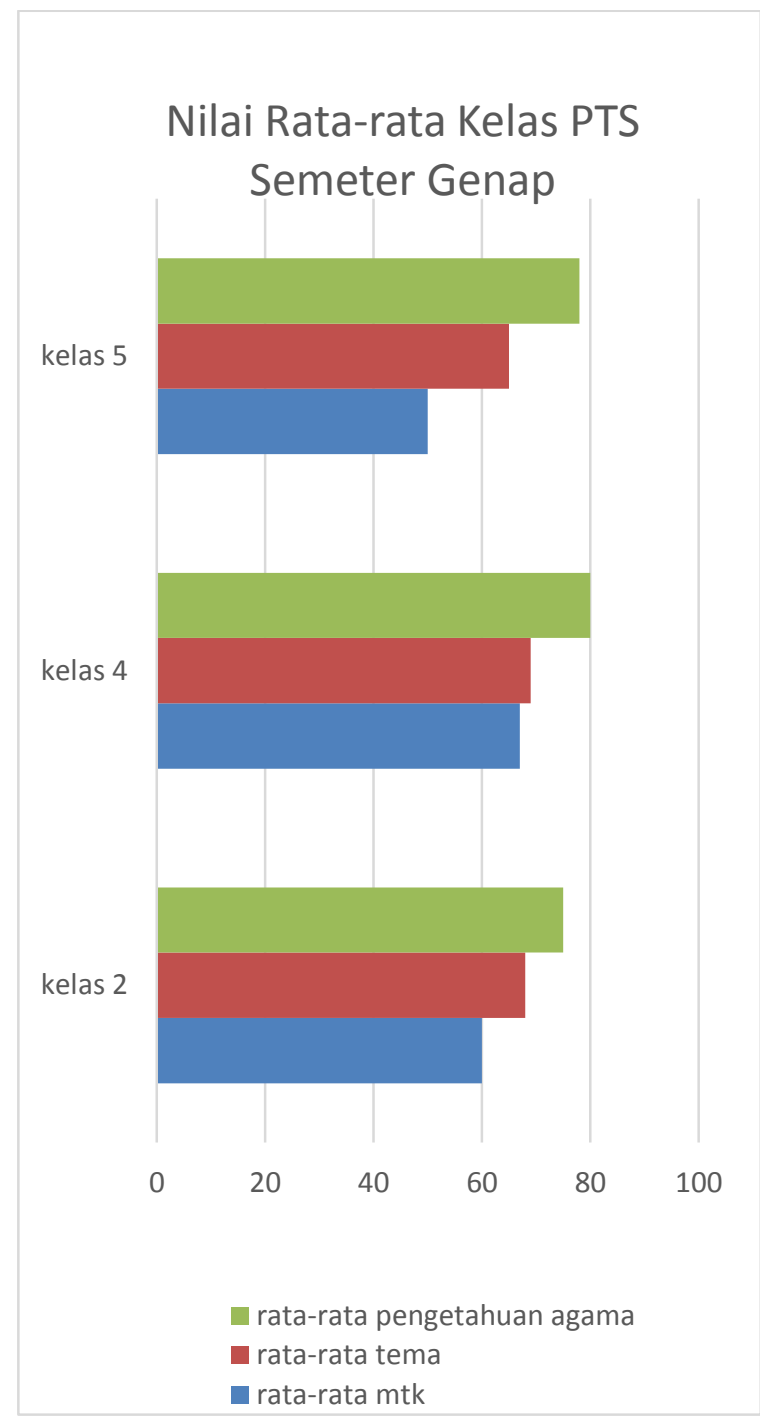

Chart di atas menunjukan bahwa hanya rata-rata pengetahuan agama saja yang yang melampaui kriteria minimal. Disamping terdapat metode pelaksanaan yang jelas dan terarah peserta didik menuis materi di rumah dan akan diterangkan guru pada saat pertemuan dengan guru 1 minggu sekali. Faktor lainnya yakni, tingakt kesulitan materi disemeter genap lebih sulit dari semester ganjil. Namun, secara keseluruhan nilai yang diperoleh lebih baik dari semester ganjil.

\section{Kesimpulan}

Perubahan kebijakan pelaksaan dari tidak ada tatap muka di semester ganjil menjadi ada tatap muka satu minggu dua kali. Menjadikan perubahan yang siginifikan pada peserta didik. Terutama padahal pemahaman dan motivasi belajar peserta didik. Secara keseluruhan pelaksanaan daring berjalan dengan baik dan sesuai dengan yang dijadwalkan. Hanya motivasi peserta didik lebih bersemangat saat pembelajran dilakukan dengan guru dan teman sekelasa mereka. Untuk kelanjutaan dari pembelajaran butir-butir yang lemah yang disebabkan oleh faktorfaktor kompetensi Pembina itu harus ditingkatkan.

Evalusi produk/hasil dari pembelajaran daring menyatakan Peserta didik dapat memahami materi yang diterangkan pendamping. Akan tetapi, kurang memahami penerapan pada soal yang diberikan oleh guru. Hasil penilaian pada tengah semester ganjil dan genap menunjukan bahwa ada perubahan yang 
signifikan. Hasil tersebut menunjukan pelaksanaan yang dikolaborasikan antara daring dan luring menjadikan peserta didik lebih memahami dan mengerti materi yang disampaikan.

\section{Saran}

Berdasarkan hasil evalusi beberapa butir evaluasi proses dan produk. Peneliti menyarakan;

1. Mengadakan pembinaan tentang pemahaman Pembina terkait tujuan pembelajaran oleh pihak sekolah/pengasuh pondok.

2. Adanya kerjasama yang terjalain antara guru dan Pembina untuk mengadakan pertemuan khusus peserta didik yang mondok di P.P. BAitul Makmur, sehingga pembelajaran lebih efektif.

Pihak sekolah melibatkan Pembina dalam rapat sosialisasi pelaksanaan pembelajaran daring sebagai wali dari beberapa peserta didik yang bersekolah di lembaga tersebut.

\section{Daftar Pustaka}

Daryanto, 2012. Evaluasi Pendidikan; Komponen MKDK, Rineka Cipta;Jakarta.

Fathurrohman, Muhammad dkk, 2012. Belajar \& Pembelajaran (Meningkatkan Mutu Pembelajaran Sesuai Standar Nasional), Yogyakarta: Teras.

Hasan, S. Hamid, 2012. Evaluasi Kurikulum, Bandung, Rosda Karya, Cet. Ke-2.

Mujib dan Mudzakir, 2008 Ilmu Pendidikan Islam, Jakarta; Kencana

Munir, M.I.T. 2010. Kurikulum Berbasis Tekhnologi Informasi
Komunikasi. Alfabeta. Bandung.

Stufflebeam, Daniel L., 2007. Evaluation Theory, Models, and Applications, Jossey-Bass;San Francisco.

Sudijono, Anas, 2005. Pengantar Statistik Pendidikan, Jakarta; Raja Grafndo.

Sudjana, Nana, 2011. Pembinaan dan Pengembangan Kurikulum di Sekolah, Bandung: Sinar Baru.

Sukmadinata, M. 2004. Evaluasi Pendidikan Prinsip dan Operasionalnya, Jakarta; Bumi Aksara.

Undang-Undang No. 20 Tahun 2003 Pasal 58 Ayat 1 Dan 2

Zhang, Guili, Nancy Zeller, dkk, 2011. Using the Context, Input, Process, and Product Evaluation Model (CIPP) as a Comprehensive Framework to Guide the Planning, Implementation, and Assessment of Service-learning Programs, Gorgia; Journal of Higher Education Outreach and Engagement, Volume 15, Number 4, p. 57. http://files.eric.ad.gov/fultext/EJ9571 07.pdf. 11.00 WIB. 17 Juni 2021. 